\title{
Herpes Labialis and Oral Candidiasis in HIV-infected intravenous drug users with poor hematologic status
}

\author{
Irna Sufiawati*, Harum Sasanti** \\ *Department of Oral Medicine Faculty of Dentistry Universitas Padjadjaran \\ ${ }^{* *}$ Department of Oral Medicine Faculty of Dentistry Universitas Indonesia
}

\section{ABSTRACT}

Hematologic abnormalities are common in HIV-infected patient, particularly in individuals with more advanced HIV disease. Hematologic abnormalities and their association with HIV-associated oral lesions had been reported. Intravenous drug use has been associated with increased oral lesions too. We reported a case of oral lesions in a 24 years old man HIV-infected intravenous drug users. Poor hematologic status is a risk factor of Oral Candidiasis in HIV-infected person with clinical features appear generally. But clinical feature of Herpes Labialis is not usually because his poor hematologic status. It's concluded that poor hematologic status and transmission of HIV through contaminated needlestick are the high risk factors of oral lesions and appear not usually clinical features in ODHA. Correction of these hematologic abnormalities and appropiately management of oral lesions can minimize the severity and to increase the better quality of life patient.

Key words: HIV/AIDS, oral lesions, hematologic, intravenous drug users

\section{INTRODUCTION}

Most HIV infected patients have neck-head manifestation during the disease course. ${ }^{1,2}$ Studies show that $70-90 \%$, even more than $90 \%$, of the HIV infected people will have at least one oral manifestation. ${ }^{3-5}$ The HIV related oral lesion has been considered as one of the clinical indicators of HIV infection in undiagnosed individuals $s^{6,7}$, a clinical classification and stage marker for HIV, ${ }^{3}$ predictor of HIV progression ${ }^{7,8}$, and indicator for poor prognosis. ${ }^{1}$ Oral candidiasis is the early sign of HIV/AIDS infection 9,10 , and able to predict the disease progression. ${ }^{11,12}$ Herpes Simplex Virus (HSV) is the cause of oral mucous ulceration often seen in HIV infected patients. The recurrent oral HSV infection that is most frequently found is Herpes Labialis. ${ }^{2,13}$

Various hematological disorders are seen in HIV infected patients. ${ }^{14-16}$ Hematopoiesis failure, immune-mediated cytopenia and changes in general coagulation mechanism are found in HIV infected patients. ${ }^{14}$ Kerdpon et al. ${ }^{17}$ reported the relationship between the abnormality of peripheral blood with oral lesion related to HIV. Furthermore, several studies on intravenous drug users (IVDU) AIDS patients have reported an increase incidence of oral lesion..$^{18,19}$ Nittayananta et al. ${ }^{20}$ also reported the influence of HIV transmission route to oral lesion prevalence.

We will report a case where Oral Candidiasis 
and Herpes Labialis are seen in an IVDU who are infected by HIV with poor hematological status accompanied by various opportunistic systemic diseases. We will try to discuss the hematological abnormality and HIV infection transmission route as a risk factor of oral lesion development in this patient as well as the clinical features and management of the disease.

\section{CASE REPORT}

On 10 November 2005, a 24 year old male was referred from the In-patient Department of Cipto Mangunkusumo Central Hospital with a working diagnosis of AIDS accompanied by lung tuberculosis, hyponatremia, multiple shallow ulcers on lips, coated tongue and dental caries for oral evaluation and management. The patient complained about the ulcers, that was painful and occasionally bleed, on his lips since 1 month ago.

The patient was admitted to the hospital since 9 October 2005 after complaining for two months before the admission. The complain include high fever, pain in upper abdomen, decrease appetite, frequent cough, night sweat, weight loss (from $56 \mathrm{~kg}$ to $47 \mathrm{~kg}$ ). Patient was admitted in hospital several times before. The last time he was admitted in a private hospital due to high fever for 4 days. On 8 October 2005, an ELISA assay was performed and he was stated as HIV positive. The patient wore right eye prosthetic after a trauma from a fight. He has been using illicit drug through injection since he was in junior high school (1996) and has a history of alcohol addiction.

The final clinical problem conclusion includes AIDS, lung tuberculosis, hyponatremia, hypochrome microcytic anemia, Herpes simplex infection suspect, difficult intake, external hemorrhoid, dyspepsia, toxoplasmosis, hepatitis $\mathrm{C}$, and thrombocytopenia. The treatment given includes Stavudin $3 \times 30 \mathrm{mg}$, Lamivudin $2 \times 1$ tab, Neviral $2 \times 1$ tab., Cancid $1 \times 150 \mathrm{mg}$ tab, Cotrimoxazol $1 \times 480 \mathrm{mg}$ tab., Mycostatin drip $3 \times 1 \mathrm{cc}$, Rifampicin $450 \mathrm{mg} /$ Isoniazid $300 \mathrm{mg} /$ Pirazinamid $750 \mathrm{mg} /$ Etambutol $1000 \mathrm{mg}$, Vitamin B6 3x1 tab, Ciprofloxacin $2 \times 200 \mathrm{mg}$ drip, IVFD $\mathrm{NaCl} 0,9 \% 500 \mathrm{cc} / 8$ hour, Pack Red Cell $300 \mathrm{cc}$ transfusion, Acyclovir cream, soft diet of 2100 calories, Transamin inj. 3x1, Pantozol 1x40 mg, Metoclopramide inj. 3x1, Fansidar $2 \times 1$ tab., and
Folic acid $2 \times 1$ tab. The peripheral blood test during treatment in hospital can be observed in the following table and chart.

On 11 October 2005, the cell count result (CD4) showed a value of $41 \mu \mathrm{l}$, representing poor immune status. On 18 October 2005, a culture from throat swab and faeces was made with a result of Candida colony growth. On 1 November 2005, information showing an IgG anti Toxoplasma positive ( $>300.0 \mathrm{UI} / \mathrm{mL}$ ), anti HSV I Ig G positive $\mathrm{OD}=2.90 \quad(\mathrm{CO}=0.90)$ and Anti HSV II IgG positive $O D=1.20(C O=0.90)$ were found.

On extra oral examination, yellowish crusts were found on the upper lip while reddish crusts were found on the lower lip accompanied by bleeding and fissured lip corner (Fig. 1a). The intraoral examination showed a poor oral hygiene with sub and supra gingival calculus, debris and staining. White plaque showing erythematous base during removal on left and right buccal mucous and left mucobuccal fold was found (Fig. 1b,c). There was yellow whitish thick coating on the tongue dorsum, shallow fissure on the median and pigmentation on dorso-lateral (Fig. 1d).

A working diagnosis was made on 10 November 2005, i.e. Herpes Labialis suspect, Oral Candidiasis (pseudomembrane and angular cheilitis), Chronic Marginal Gingivitis. A treatment in the form of dental health education that includes maintain correct and regular tooth brushing, tongue brushing, instruction to wipe the entire teeth and oral mucous with sterile bandage soaked in mouthwash that contains chlorhexidine gluconate $0.2 \%$. Lip cream (Acyclovir cream) provided by the doctor was used.

On 14 November 2005, patient felt that the lip wounds were improved and he was able to eat well. The lip corner was still painful and easily bled. On extra oral examination, yellowish crusts were still found, especially in 1.3 region and dark red crusts were found on lower lip in 3.1,3.2,4.1,4.2 regions with bleeding was still seen. Fissure on the lip corner accompanied by bleeding was also seen (Fig. 2a). On intraoral examination, whitish plaque with erythematous base during removal on upper and lower mucous was still found (Fig. $2 b)$ as well as on posterior palatum durum which was not found during the first visit. Along the occlusal line and posterior region on right and left buccal mucous, there was increased amount 


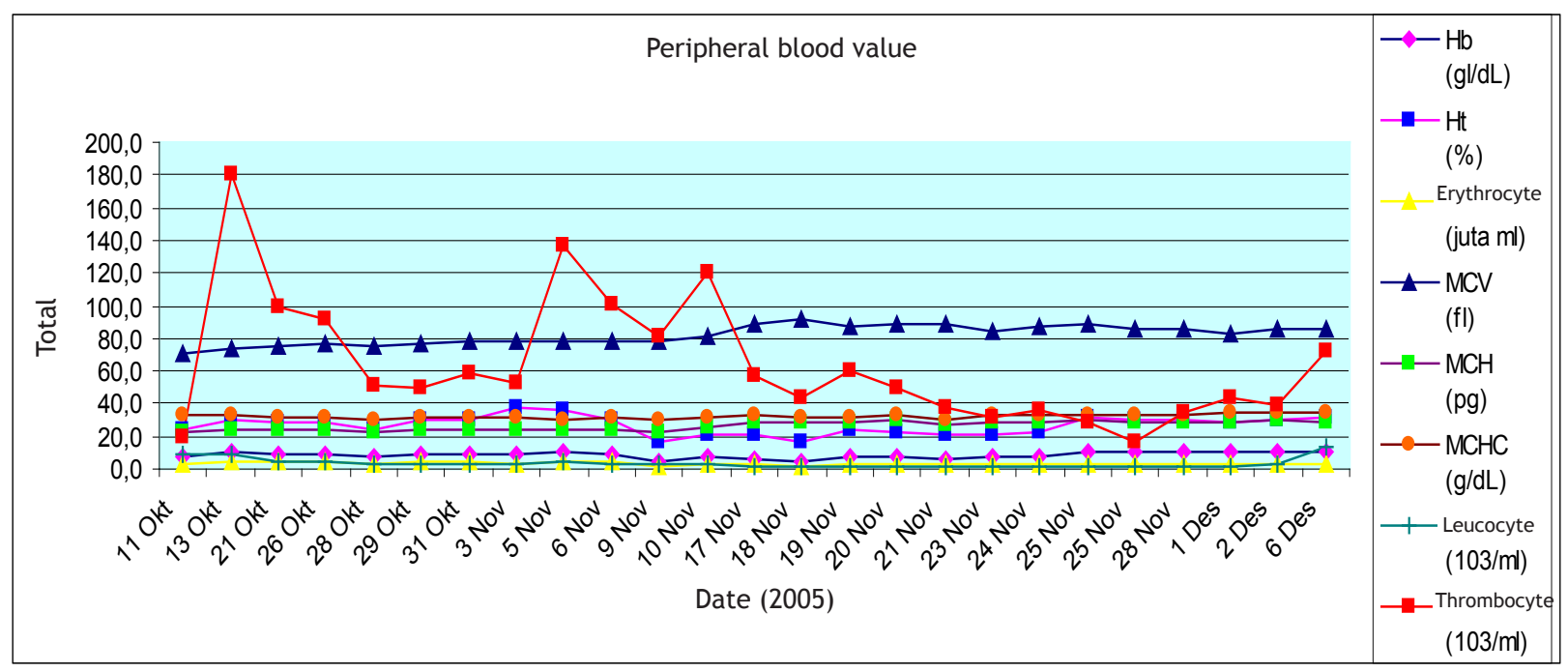

Graphic 1. Peripheral blood value feature showing patient's hematological status.

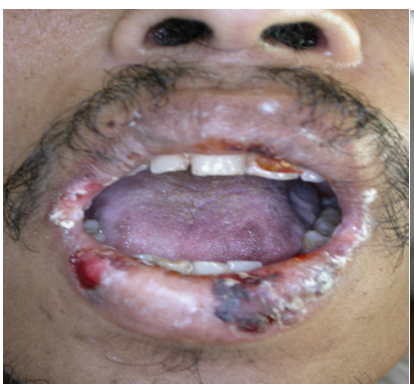

a

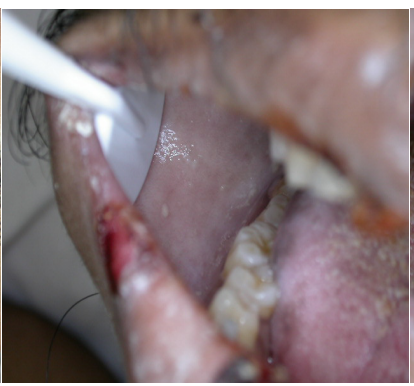

b

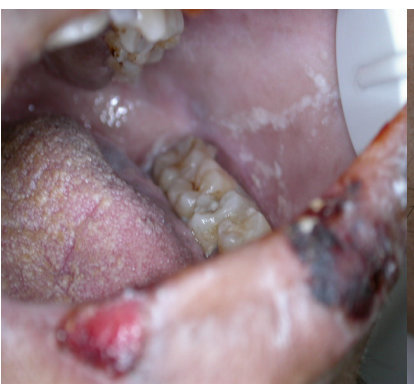

c

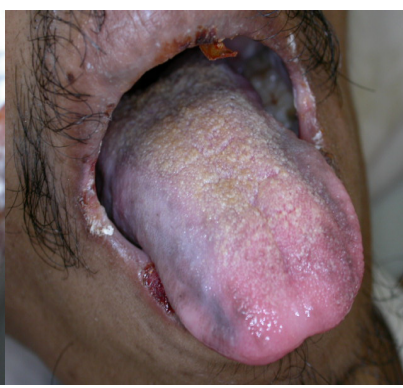

d

Figure 1. Yellowish crusts on upper lip are seen while reddish crusts on lower lip with bleeding and fissured lip corner are also apparent (a). Whitish plaque that can be removed by mild pressure, leaving erythematous base on right-left buccal mucous $(b, c)$. White yellowish coated tongue on tongue dorsum and pigmentation on tongue dorso lateral area (d).

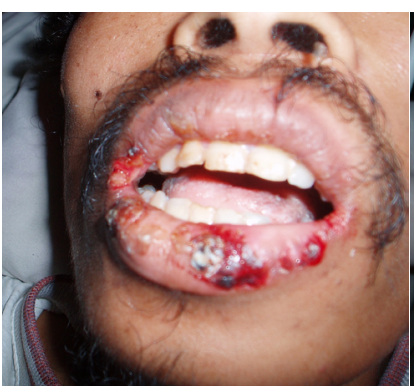

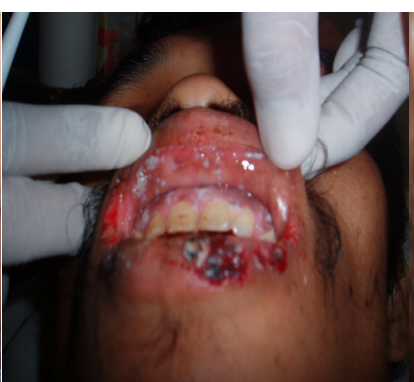

b

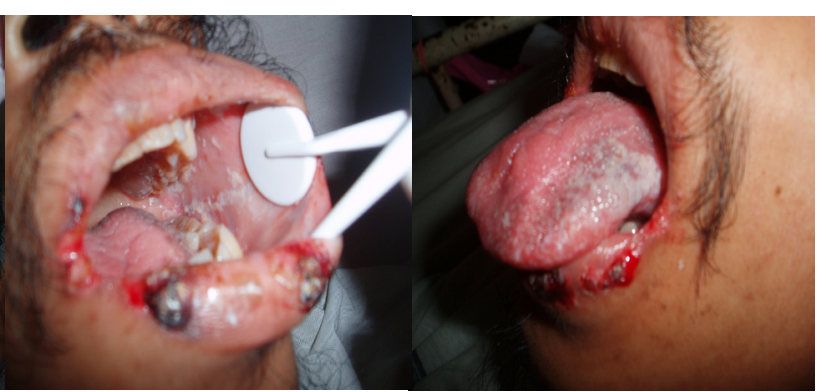

c

d

Figure 2. There are still yellowish crusts on upper lip, dark red crusts on lower lip with bleeding and fissured lip corner with bleeding. (a). White plaque on labial mucous is seen as well as along the buccal mucous occlusal line. On the tongue lateral area, the plaque amount increases and thickens $(c, d)$.

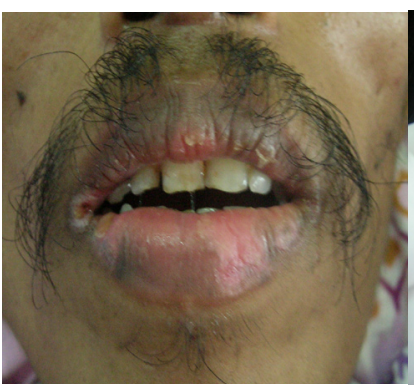

a

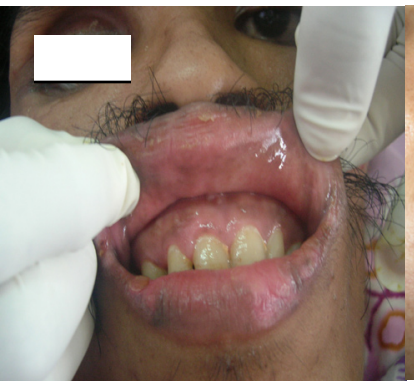

b

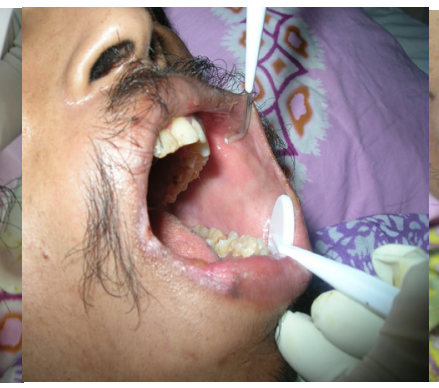

C

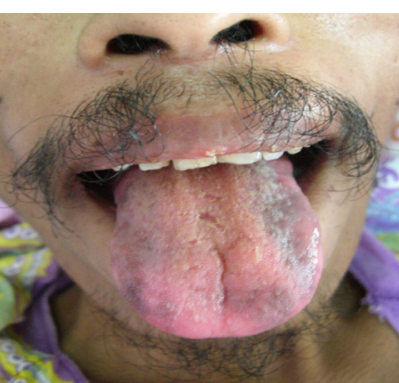

d

Figure 3. Improved Herpes Labialis and Oral Candidiasis. 
of thickening whitish plaque (Fig. 2c). Thinning coated tongue was seen but removable whitish plaque that left erythematous base on the lateral part during removal was also seen (Fig. 2d). The drop prescribed by the doctor (mycostatin oral suspension) was not purchased so the patient did not use this medicine. An additional systemic therapy from the internal medicine was given, i.e. Acyclovir tab. $5 \times 200 \mathrm{mg}$ per oral, and Fluconazole $1 \times 150 \mathrm{mg}$ per oral. We kept giving dental health education and instruction to continue using chlorhexidine gluconate $0.2 \%$.

On 28 November 2006, the wounds on the lips were recovering and the patient felt that his oral cavity condition was much better. On extra oral examination, crusts on the upper and lower lips were less and there was no bleeding seen. However, the fissure on the lip corner was still presence (Fig. 3a). On intraoral examination, there was no clinical feature of oral candidiasis (Fig. 3b,c,d). Patient still received treatment for the systemic problem that he had, which was similar to the previous visit. The patient was instructed by the doctor to stop the lip cream. We still recommended continuing the mouth wash to the patient to maintain his oral hygiene and when the condition got better, it was recommended to perform scaling due to poor oral hygiene.

\section{DISCUSSION}

Based on the patient medical record in this case, the hematological test results during patient's stay in the hospital show various blood disorders. Patient had anemia, thrombocytopenia, leucopenia and lymphopenia. The hematological disorders in this patient may happen due to the HIV infection itself which was already in the advance stage, as a sequel of the opportunistic infections (lung TB and toxoplasmosis) or as the consequences of the HIV infection therapy itself, i.e. antiretroviral agents (Stavudin, Lamivudin, Neviral) consumed by the patient. ${ }^{14}$ Anemia in this patient relates to progression of HIV infection, opportunistic infection, nutrition deficiency (difficult intake) and medicine use. ${ }^{21-23}$ Thrombocytopenia in this patient is suspected as being triggered by several possibilities including opportunistic infection, HIV antigenemia increase (although unproved), and hematopoeisis failure and toxic effect of medicines. ${ }^{14,15}$ Leucopenia is caused by lymphocyte CD4 deficiency, which was supported by the result of the assay that shows a value of $41 \mu \mathrm{l}$. This represents a severe immunosupression status of this patient. ${ }^{15}$

Based on the subjective and objective examinations of this patient, the Oral Candidiasis and herpes labialis diagnosis was made. The present oral lesions are possibly related to the poor hematological status of the patient. Literatures stated that there is a relationship between peripheral blood abnormalities with HIV related oral lesions. Kerdpon, et al. ${ }^{17}$ reported that lymphopenia significantly relates to increase HIV related oral lesion, including oral candidiasis. Lymphopenia can be used as the predictor of HIV related oral lesion incidence especially when the CD4 and viral load value cannot be measured routinely. ${ }^{17}$ Patton ${ }^{15}$ reported that one or more of 20 oral manifestation of HIV infection or 2 most frequent lesions such as oral candidiasis and hairy leukoplakia are significantly related to anemia, leucopenia, and lymphopenia, but not neutropenia. Various studies reported the relationship between the low number of CD4 T cells and the oral lesion prevalence in HIV patients, both those under ART and those with no ART. ${ }^{24}$

The Herpes Labialis diagnosis in this case is supported by the immunological examinations showing that the patient has been infected by HSV-1 and HSV-2. Literatures stated that due to the high prevalence of HISV infection, a lot of HIV infected people are also infected by HSV-1 and/ or HSV-2. HSV-2 infection is usually transmitted through sexual activities. Someone who gets HIV through sexual contact also has a high risk of HSV-2 infection. Herpes simplex virus- 2 can become HIV transmission co-factor or as the sexual risk sign. ${ }^{25,26}$ Therefore, in this case, the HIV transmission is suspected not only through contaminated needle but also through sexual contact.

HIV and herpes virus interaction in oral mucous, i.e. herpes virus in oral mucous, can affect HIV replication in the mouth. ${ }^{27}$ Mole et al. ${ }^{28}$ reported that RNAHIV level can also increase during active HSV infection where acute HSV infection episode can lead to HIV transcription and plasma viral load increase. It can be concluded that this patient had a high viral load during recurrent HSV infection (active). The triggering factors were 
decreased immune system (number of Th cells CD4 $41 \mu \mathrm{l}$ ) and emotional stress experienced by the patient. A literature stated that there is a relationship between emotional stress (daily life, life changing events, anxiety) with the recurrent nature of herpes labialis. ${ }^{29}$

The clinical feature of herpes labialis in this case was different from immunocompetent patient, i.e. reddish crust on the lips accompanied by spontaneous bleeding around the lesions. This might relate to the poor hematological status (thrombocytopenia leading to vulnerability to bleeding). Moreover, the lesions have been seen for more than 1 month showing that the patient has already in AIDS stage. Literatures stated that the definition of AIDS according to The Centers for Disease Control includes HIV seropositive patient with orofacial herpetic lesion that has been presence for more than 1 month. ${ }^{8}$

The Herpes Labialis therapy in this patient was acyclovir cream applied on the lips 4-6x/day and the response to this treatment took a quite long time (about 1 month). According to the literature, in immunocompromized patients, herpes lesion spreads broader, slow to cure and refractory to treatment. ${ }^{30}$ The patient also received mouthwash that contains chlorhexidine gluconate $0.2 \%$ (CHX) to treat gingivitis and oral candidiasis as well as expected to affect HSV infection because $\mathrm{CHC}$ has a synergic antiherpetic effect when combined with Acyclovir. ${ }^{31}$ In this case, oral candidiasis diagnosis is made based on the clinical features and supported by culture examination. It is acknowledge that hematological disorder is one of the risk factors of oral candidiasis susceptibility. Literatures stated that oral candidiasis often relates to HIV infection. Therefore, blood folic acid level, vitamin B-12, iron, hemoglobin, lymphocyte, and white blood cell counts are important. ${ }^{16}$ Chattopadhyay ${ }^{11}$ emphasized that low CD4 cell count is an important risk factor for oral candidiasis and antiretroviral medicine can prevent oral candidiasis development. ${ }^{10}$ On the contrary, antiretroviral drug use, especially zidovudine, may increase the risk of reduced hematocrit level. The use of antiparasitic medicine, especially trimethoprim-sulfamethoxazole (TMPSMX), significantly relates to decreased level of each hematological variable. ${ }^{15}$

$\mathrm{Campo}^{12}$ reported oral candidiasis related to high viral load (>10.000), low percentage of lymphocyte CD4, and intravenous drug user (compared to heterosexual transmission) Based on the study, oral candidiasis may be useful as a clinical marker that the patient has a high viral load. In addition, oral candidiasis can also be used as HIV infection progression marker in this patient. The patient was given Mycostatin oral suspension (nistatin) to be rinsed and swallowed, $1 \mathrm{ml} 4$ times a day and the $\mathrm{CHX}$ containing mouthwash that has anti-fungus effect by wiping it to all oral mucous. The result was the oral candidiasis improved 2 weeks after the treatment was started.

HIV infection transmission in this intravenous drug user is probably through HIV contaminated needle because the needle was shared. Based on the literature search it is stated that HIV transmission route may increase oral lesion development. Barone, et al. ${ }^{19}$ reported that of 217 HIV infected patients, $65 \%$ of the patients are intravenous drug abusers (IVDAs). The most frequent lesion is candidiasis, found in $31.3 \%$ patients while herpes labialis is found only in a small number of patients $(1.3 \%)$. Lamster, et al. ${ }^{18}$ reported that the percentage of Candida infection in seropositive intravenous drug users (IVDU) is higher than in HIV (+) homosexual men. The use of intravenous opiate may cause decreased cellular immunity that could trigger viral and fungal infection IVDU. Besides, other factors that potentially affect intraoral Candida infection among IVDUs are poor health care, poor diet, increased dental plaque accumulation, caries, periodontal disease and the high percentage of Candida infection before HIV infection. ${ }^{18}$

\section{CONCLUSION}

The poor hematological status and HIV transmission route through contaminated needle could increase the risk of oral lesion and give unusual clinical feature in HIV infected patients. Correction of the hematological abnormalities and appropriate oral lesion management can reduce oral lesion severity and improve HIV patient quality of life. 


\section{REFERENCES}

1. Agbelusi GA, Wright AA. Oral lesions as indicators of HIV infection among routine dental patients in Lagos Nigeria. Oral Disease 2005;11:370-3.

2. Moazzez AH, Alvi A. Head and neck manifestations of AIDS in adults. J Am Fam Phys 1998;57(8).

3. Vaseliu $\mathrm{N}$, Kamiru $\mathrm{H}$, Kabue $\mathrm{M}$. Oral Manifestations of HIV infection. HIV Curriculum for the Health Profesional. [cited 2005 Nov 17]. Available from: http://bayloraids.org.

4. Weinert M, Grimes RM, Lynch DP. Oral manifestations of HIV infection. Ann Intern Med 1996;125(6):485-96.

5. Anteyi KO, Thacher TD, Yohanna S, Idoko JI. Oral manifestation of HIV-AIDS in Nigerian patients. Int J STD \& AIDS 2003;14:395-8.

6. Coogan MM, Greenspan J, Challacombe SJ. Oral lesions in infection with human immunodeficiency virus. Bulletin of the World Health Organ 2005;83(9):641-720.

7. Greenspan JS, Greenspan G. The Epidemiology of the oral lesions of HIV infection in the developed word. Oral Disease 2002;8(2):34-9.

8. Fischman SL. Oral health in HIV disease. HIV Medical Alert 2004;8(1).

9. Fichtenbaum CJ, Aberg JA. Candidiasis and HIV. 2006 Feb. [cited 2006 Maret 30]. Available from: http: / /hivinsite.ucsf.edu.

10. Chattopadhyay A, Caplan DJ, Slade GD, Shugars DC, Tien H-C, Patton LL. Risk indicators for Oral Candidiasis and Oral Hairy Leukoplakia in HIV-infected adults. Community Dent Oral Epidemiol 2005;33:35-44.

11. Chattopadhyay A, Caplan DJ, Slade GD, Shugars DC, Tien H-C, Patton LL. Incidence of Oral Candidiasis and Oral Hairy Leukoplakia in HIV-infected adults in North Carolina. Oral Surg Oral Med Oral Pathol Oral Radiol Endod 2005;99:39-47.

12. Campo J, Del Romero J, Castilla J, Garcia S, Rodriguez C, Bascones A. Oral Candidiasis as a clinical marker related to viral load, CD4 lymphocyte count and CD4 lymphocyte percentage in HIV-infected Patients. J Oral Pathol Med 2002;31:5-10.

13. Phelan JA, Kerpel SM, Freedman PD. Oral Mucosal Herpes Simplex ulceration in an HIV- seropositive man. AIDS Read 1999;9(1):35-6.

14. Northfelt DW. Hematologic manifestations of HIV. HIV insite knowledge base chapter. 1998. [cited 2006 Maret 16]. Available from: http:// hivinsite.ucsf.edu.

15. Patton LL, Hill C. Hematologic abnormalities among HIV-infected patients associations of significance for dentistry. Oral Surg Oral Med Oral Pathol Oral Radiol Endod 1999;88:561-7.

16. Claster S. Biology of anemia, differential diagnosis, and treatment options in Human Immunodeficiency Virus infection. J Infect Dis 2002;185:105-9.

17. Kerdpon D, Sretrirutchai S, Nilmanut A, Geater A, Wangrangsimakul K. The Association of peripheral blood abnormalities and HIVassociated oral lesions. $5^{\text {th }}$ World Workshop on Oral Health and Disease in AIDS. Last Updated October 12, 2005. [cited 2006 Maret 15]. Available from: http://www.hivdent.org/... htm.

18. Lamster IB, Begg MD, Mitchell-Lewis D, Fine JB, Grbic JT, Todak GG, et al. Oral manifestations of HIV Infection in heterosexual men and intravenous drug users. Study design and relationship of epidemiology, clinical, and immunologic parameters to oral lesions. Oral Surg Oral Med Oral Pathol 1994;78:163-74.

19. Barone R, Ficarra G, Gaglioti D, Orsi A, Mazzotta F. Prevalence of oral lesions among HIV-infected intravenous drug abusers and other risk groups. Oral Surg Oral Med Oral Pathol 1990;69:169-73.

20. Nittayananta W, Chanowanna N, Sripatanakul S, Winn T. risk factors associated with oral lesions in HIV-infected heterosexual people and intravenous drug users in Thailand. J Oral Pathol Med 2001;30:224-30.

21. Molaghan JB. The facts about HIV-Related anemia. The Body 1999. [cited 2006 Maret 30]. Available from: http://www.thebody. com/molaghan/anemia.html.

22. Sullivan PS, Hanson DL, Chu SY, Jones JL, Ward JW. Epidemiology of anemia in Human Immunodeficiency Virus (HIV)-Infected persons: results from the multistate adult and adolescent spectrum of HIV disease surveillance project. Blood 1998; 91(1):301-8.

23. National Anemia Action Council. Anemia and HIV/AIDS. 2005. [cited 2006 Maret 30]. 
Available from: http://www.anemia.org/ patients/warning_signal.jsp.

24. Tappuni AR, Fleming GJP. The Effect of antiretroviral therapy on the prevalence of Oral manifestations in HIV-infected patients: A UK study. Oral Surg Oral Med Oral Pathol Oral Radiol Endod 2001;92:623-8.

25. Erlich KS. Herpes Simplex Virus and HIV. HIV InSite knowledge base chapter. 2003 Jun. [cited 2006 Maret 17]. Available from: http:// hivinsite.ucsf.edu.

26. Bartlett JG. Recent development in the management of Herpes Simplex infection in HIV-infected persons. Clin Inf Dis 2004;39:2379.

27. Mbopi-Keou FX, Mbu RE, Gonsu Kamga H, Kalla GCM, Monny Lobe, M, Teo CG, et al. Interaction between Human Immunodeficiency Virus and Herpes viruses within the oral mucosa. Clin Microbiol Infect 2005;11:83-5.

28. Mole L, Ripich S, Margolis D, Holodniy M. The Impact of active Herpes Simplex Virus infection on Human Immunodeficiency Virus load. J Infect Dis 1997;176:766-70.

29. Augustin M. Education in psychodermatology: Herpes Labialis and genitalis. Dermatol Psychosom 2001;2:208-10.

30. McCullough MJ, Savage NW. Oral viral infections and the therapeutic use of antiviral agents in dentistry. Aus Dent J 2005;50 Suppl 2:531-5.

31. Park JB, Park NH. Effect of chlorhexidine on the in vitro and in vivo Herpes Simplex Virus infection. Oral Surg Oral Med Oral Pathol 1989;67:149-53. 